both intellectual and social. Not only did he spend himself for the well-being of those in his own Group for which he was personally responsible, but he turned his energies with understanding and enthusiasm to the individual and collective care of every member of the community. His interests went far beyond work, for he could also play: an expert sailor, an unusually good photographer, and a student of geology, his life was fuller and probably happier than that of most men.

He is survived by a widow and two boys, to whom as well as to his mother, his many friends extend their sympathy.

\title{
Cyril Hutchinson Walker
}

Mr. Cyril H. Walker, M.B., F.R.C.S., died at his home in Bristol at the age of 94. He was born in Yorkshire, studied at Haileybury and Jesus College, Cambridge, carried out his medical studies at the London Hospital, and qualified M.B. in 1887. He became junior and later senior house surgeon at Moorfields; in 1900 he was appointed ophthalmic surgeon to the Bristol General Hospital, and then surgeon to the Bristol Eye Hospital. He was lecturer in ophthalmology to the University of Bristol, Master of the Oxford Ophthalmological Congress (1933 and 1934), President of the Ophthalmological section of the Royal Society of Medicine, and Vice-President of the Ophthalmological Society of the United Kingdom (1921 to 1924). He resigned from practice in 1933, occupying his leisure with his garden of which he was very fond.

As one of his students at the General Hospital, and house surgeon and colleague at the Bristol Eye Hospital, I owe a considerable debt to Mr. Walker. He was very helpful to all who had the privilege of working with him, and an excellent teacher who had the gift of being able to impart his knowledge to others. He was unassuming, with a fund of quiet humour; his advice was always very sound, and he was of great assistance in planning and carrying out the rebuilding and reconstruction of the Bristol Eye Hospital, thus helping to maintain the standard of ophthalmology in Bristol, which he and Mr. Richardson Cross had done so much to improve.

A. E. ILES

\section{NOTES}

\section{OXFord OPhThalmological CONGResS}

THE next meeting will be held on July 2, 3, and 4, 1956. Dr. Jonas S. Friedenwald of Baltimore has accepted the Doyne Lectureship.

\section{HONOURS}

ON October 3, 1955, Sir Stewart Duke-Elder received a doctorate honoris causa in the Faculty of Medicine from the University of Ghent, together with the Medal of the University.

MR. F. W. LAW has been elected Master of the Worshipful Company of Spectacle Makers for the year 1955-56.

\section{CORRIGENDA}

In the article by Leo E. Lipetz on X-Ray and Radium Phosphenes, British Journal of Ophthalmology (1955), 39, 577 :

p. $580,1.19$ from bottom, for $\mathrm{mm}$. read $\mathrm{mm} .^{2}$

1. 12 from bottom, insert bracket after ' intensity', delete bracket after ' phosphene'.

p. 595, 1. 3 from bottom, insert ' ;' after ' 620 ', delete ', ' after 'English'

p. 597, 1. 9 from top, insert ';' after '(July)' delete ';' 'after '(German)'

1. 17 from top, insert ' ;' after 206.

1. 8 from bottom, insert ' $\$$ before ' $A t t i$ '

p. $598,1.12$ from top, for '.' read ' ',

1. 13 from top, delete initial rule and run on from previous line. 